\title{
DILTHEY - CONCEITO DE VIVÊNCIA E OS LIMITES DA COMPREENSÃO NAS CIÊNCIAS DO ESPÍRITO ${ }^{1}$
}

\author{
Maria Nazaré de Camargo Pacheco AMARAL ${ }^{2}$
}

- RESUMO: O propósito sistemático-filosófico da crítica diltheiana da razão histórica traduz-se na busca de apoio do conhecimento objetivo para sua apreensão intuitiva da vida. O presente artigo busca mostrar não só aspectos da trajetória teórica do autor, mas também suas dificuldades e limites.

- PALAVRAS-CHAVE: vivência, expressão, compreensão, auto-reflexão, espírito objetivo

\section{Objetivação da vida: vivência e realidade}

A experiência de resistência do movimento e de inibição da vontade sofrida por nós no meio em que vivemos constitui, para Dilthey, a origem mais elementar de nossa crença na realidade do mundo exterior. Contrariamente ao que outros filósofos têm tentado fazer, isto é, provar ou contestar a existência do mundo exterior apoiados na lógica da razão, Dilthey prefere fazer repousar a sua "prova" em uma crença. O homem se exercita no jogo vivo entre impulso e resistência, jogo a partir do qual se organiza o nexo adquirido de nossa vida psíquica. Ora, esse nexo adquirido extrai sua vitalidade da totalidade de nossas forças psí-

\footnotetext{
1 Texto da conferência proferida no Simpósio "Limites da Compreensão" realizado no Centro Universitário de Witten, Alemanha em junho de 2000.

2 Professora da faculdade de Educação da USP.
} 
quicas ao experimentarmos a resistência de nossos impulsos, ou em outras palavras, da totalidade de nossas vivências.

Em substituição à experiência mutilada da realidade, oferecida pelo sujeito cognoscente da filosofia tradicional do conhecimento, Dilthey oferece-nos o conceito de vivência, símbolo verdadeiro da experiência "plena e não mutilada" da realidade igualmente "plena e total" ${ }^{3}$

Uma observação de Frithjof Rodi em relação ao conceito de vivência faz-se oportuna: "Este conceito Erlebnis que deve expressar a totalidade da relação com a realidade transformou-se, sob influência de Dilthey, em uma das palavras mais em voga dentro da filosofia alemã do século XX". 4

Poderíamos dizer que, ao se projetar para além dos limites da filosofia diltheyana, a palavra Erlebnis apenas deu vazão à força de conceito fundamental que tem para o pensamento de seu autor. Uma prova da importância desse conceito encontra-se naquilo que constitui a tese basilar do pensamento de Dilthey: "As ciências do espírito estão, assim, fundadas nesse nexo de vivência, expressão e compreensão". ${ }^{5}$ No relacionamento desses três pilares sustenta-se para Dilthey a possibilidade de construção e compreensão do mundo histórico, como conquista valiosa das ciências do espírito.

Poderíamos começar argumentando que vivência é a própria vida reduzida nas suas proporções mais diminutas e ao mesmo tempo mais fidedignamente representativas do modelo em tamanho original. Poderíamos também lembrar as palavras de Dilthey em seu Tratado da Realidade (1890), salientando que a vivência, ao encerrar a própria vida é, como esta, "continuamente sua própria prova". ${ }^{6}$ Isto significa dizer que ela constitui a zona limite do conhecimento, isto é, o último fundamento do conhecimento. É como se, ao conter a vitalidade em toda a sua força de expressão, estabelecesse o marco divisório para além do qual o pensamento não tivesse acesso. Ou, ainda de outro modo, a vivência constitui o próprio critério vivo responsável pela triagem dos fatos da consciência, já que para o autor estes são dados em nossas vivências.

3 Cf. "Grundgedanke meiner Philosophie", Gesammelte Schriften, VIII, p. 171.

4 Frithjof Rodi. "W. Dilthey, Um Filósofo Desconhecido", In: O Estado de S. Paulo, Suplemento Cultura, 13/11/1983.

5 Der Aufbau der Geschichtlichen Welt in die Geisteswissenschaften, Gesammelte Shriften, VII, p. 87.

6 Cf. Gesammelte Schriften, V, p. 131. 
A condição fundamental imposta pelo princípio da fenomenalidade, para a determinação dos fatos da nossa consciência, resume-se na necessidade de eles serem vivenciados por nós. E Dilthey é categórico em sua afirmação: "Os pressupostos fundamentais do conhecimento estão dados na vida e o pensamento não pode conceber por trás deles". ${ }^{7}$ Para além dos fatos da consciência, que são dados na totalidade de nossa vida psíquica, só existe o sinal vermelho, símbolo da impossibilidade de ultrapassagem em busca de um ponto transcendentalmente sólido. Essa advertência deverá ser rigorosamente cumprida, pois caso contrário a penalidade imposta será em todos os casos, sem admitir nenhuma exceção à regra, necessariamente fatal. À menor infração a esse princípio fundamental corre-se o risco de perder a sintonia com a vida e com ela a possibilidade de compreender o mundo humano histórico-social.

Vejamos a seguir como Dilthey estabelece o relacionamento entre experiência e realidade. Dentre as denominações de sua "filosofia da vida" encontra-se também a de "filosofia da realidade" ou "filosofia da experiência", ou ainda "empiria e não empirismo". Para "todas" elas os fatos da consciência não resultam de meras operações intelectuais, de representações que não podem nunca nos oferecer a realidade plena e total, procedente apenas do cumprimento amplo e irrestrito das exigências vitais, impostas ao nosso conhecimento pela totalidade de nosso nexo psíquico. Mais ainda, fatos da consciência não se reduzem a uma esfera de imagens desconectadas das relações concretas com o mundo exterior. E é dentro dessa linha de pensamento que a vivência é erigida à condição de categoria epistemológica fundamental em oposição ao conceito de representação. ${ }^{8}$ Se ela pode ser assim considerada é porque, para Dilthey, ela contém em si as categorias teóricas do conhecimento, como formas da realidade objetiva. Todas as categorias da realidade objetiva fazem parte das vivências por constituição. É o que podemos apreender da seguinte afirmação de Dilthey, incluída em seu "Tratado da Realidade" (1890): "O valor do conhecimento da oposição do eu e do objeto não é também o de um fato transcendente, senão que

7 Idem, p. 136. Cf. também Helmut Johach, Handeln der Mensch und Objektiver Geist. Zur Theorie der Geistes und Sozialwissenschaften bei Wilhelm Dilthey, Verlag Anton Hain, Meisenheim am Glan, 1974, pp. 122-123.

8 Cf. Frithjof Rodi, "Dilthey's Concept of Structure within the Context of 19th century science and philosophy", in: Rudolf Makkreel and John Scanlon, Dilthey and Phenomenology, Center for Advanced (Editors), Reasearch in Phenomenology \& University Press of America, Washington, D. C., 1987, p. 111. 
o eu e o outro ou exterior são precisamente nada além do que é contido e dado nas experiências da própria vida. Esta é toda a realidade". 9

Poderíamos, então, dizer que em meio às condições, delimitações e restrições impostas pelo pensamento diltheyano, a realidade confundese com a vivência, isto é, o que é real é vivenciado e o que é vivenciado é realidade. A partir daí, torna-se claro para nós que o fato de existir ou não uma realidade objetiva, independentemente de nossa consciência, é uma questão desprovida de vitalidade em meio a esse cenário. Dilthey não deixa nenhuma sombra de dúvida a esse respeito em sua obra $A$ Construção de Mundo Histórico nas Ciências do Espírito (1910):

Não há ninguém nem nada que fosse para mim apenas objeto e não contivesse pressão ou estímulo, alvo de uma aspiração ou compromisso da vontade, importância, exigência a ser tomada em consideração e proximidade interior ou resistência, distância e estranheza. A referência à vida, seja ela limitada a um dado momento ou duradoura, transforma para mim esses homens e objetos em representantes de felicidade, alargamento de minha existência, aumento de minha força, ou eles restringem nessa referência o espaço da minha existência, eles exercem uma pressão sobre mim, eles diminuem minha força. ${ }^{10}$

Pelo que nos é dado perceber, as pessoas e os objetos não são frios e distantes dos nossos propósitos, mas têm significado e valor para nós, na medida em que são portadores em potencial de nossa felicidade ou desgraça, nossa alegria ou tristeza, do aumento ou diminuição de nossa energia vital, etc.

\section{Vivência e Categoria do Significado}

Tendo, então, como pano de fundo o significado dos objetos e das pessoas para nós, Dilthey "distingue" a concepção do objeto, a atribuição de valor e o estabelecimento de fins como tipos de comportamento de incontáveis nuanças que se transformam entre si. Eles se encontram no curso da vida ligados em nexos interiores que abrangem e determi-

9 Gesammelte Schriften, V, pp. 136 - 137. Cf. Georg Lukács Die Zerstörung der Vernunft Vol. II (Irrationalismus und Imperialismus), Darmstadt, Neuwied: Luchterhand, 1983, pp 100 - 123, onde o autor salienta a importância do conceito de vivência como marco central da "filosofia imperialista da vida" fundada por Dilthey.

10 Gesammelte Schriften, VII, p. 131. 
nam toda atividade e desenvolvimento". ${ }^{11}$ Dito de outro modo: conceber algo, atribuir valor e estabelecer fins para algo são atitudes vitais interdependentes que configuram as vivências e, assim sendo, nos ajudam a construir a própria realidade em que vivemos. Vivência e realidade são como que tecidas conjuntamente graças ao apoio da "categoria do significado". Afirma ele em seu Plano de Desenvolvimento para a Construção do Mundo Histórico nas Ciências do Espírito:

O nexo da vivência em sua realidade concreta repousa na categoria do significado. Esta é a unidade que toma o decurso do vivido e do revivido em conjunto na lembrança, embora o significado do mesmo não consista em um ponto de unidade que repouse para além da vivência, senão que esse significado está constitutivamente contido nessas vivências, como em seu respectivo nexo. $^{12}$

Conforme já vimos, a vivência é sua própria prova e isto não atinge somente os processos intelectuais da concepção do objeto, como também os processos afetivos envolvidos na atribuição de valor e os processos volitivos relacionados com o estabelecimento de fins, todos eles atuando aí, constitutivamente, em unidade de conjunto.

Sabemos ainda que a categoria do significado, que responde por essa unidade, não encontra seu apoio em algo transcendente à própria vivência, pois esta já contém em si todas as categorias da realidade objetiva. Para fechar o círculo, diríamos que a realidade objetiva está composta em sua totalidade pelo conteúdo vivo das vivências... Afinal, a vivência como que naturalmente se objetiva, isto é: "O conhecimento está aí, ele está ligado à vivência sem reflexão. Ele não tem nenhuma outra origem e fundamento que não seja a própria vivência". ${ }^{13}$ Apoiados nessas considerações, reiteramos a afirmação de Hans Georg Gadamer de que a "vivência tem uma estrutura hermenêutica" e que, em função disso, "ela se auto-interpreta". ${ }^{14}$

Dizer que "a vivência é sua própria prova", que "ela contém todas as categorias da realidade objetiva", que "ela naturalmente se objetiva", que "ela tem uma estrutura hermenêutica" e que assim sendo "se auto-

11 Idem, p. 132

12 Gesammelte Schriften, VII, p. 237.

13 "Studien zur Grundlegung der Geisteswissenschaften", Gesammelte Schriften, VII, p. 18.

14 Cf. H. G. Gadamer, Wahrheit und Methode Grundzüge einer Philosophyschen Hermeneutik, 2a ed. Tübigen, 1965, pp. 286, 300 - 313. 
interpreta" significa afirmar uma e mesma coisa, isto é, que vivência é não apenas o seu próprio critério de verdade, mas, como tal, a medida de todas as coisas, pois ao ser tecida em meio a uma atmosfera em que valores, significados, expressões, idéias e ideais são apreciados em comum, encontra-se como que atrelada a uma origem extra-individual. E essa origem lhe dá foros de objetividade, tornando-a a menor, mas em hipótese alguma a menos importante, célula viva do mundo históricosocial. Esse pano de fundo extra-individual da vivência encontra-se claramente descrito por Dilthey em A Construção do Mundo Histórico nas Ciências do Espírito:

Cada palavra, cada frase, cada gesto ou expressão de cortesia, cada obra de arte e cada feito histórico é somente compreensível porque há um fundo comum que une a pessoa que se manifesta com a pessoa que entende; o ser singular vivencia, pensa, age, sempre em uma esfera comum e somente nela se entende. Tudo que se compreende traz em si, por assim dizer, o marco do que é conhecido a partir de tal comunhão. Nós vivemos nessa atmosfera, ela nos envolve continuamente. Nós somos mergulhados nela. Nesse mundo histórico e compreensível estamos por toda parte em casa, compreendemos o sentido e o significado de tudo, nós próprios somos tecidos nessa coisas comuns. ${ }^{15}$

Se a vivência encontra-se por constituição atrelada a esse "meio das coisas comuns", não nos é difícil compreender que a possibilidade de a vivência expressar-se objetivamente lhe seja imanente. Isto é o que podemos depreender da seguinte afirmação de Dilthey incluída em seus "Fragmentos sobre Poética" (1909/8): "A vivência contém uma expressão. Esta representa-a em sua plenitude". ${ }^{16}$ Para não deixar dúvidas sobre essa possibilidade imanente de a vivência expressar-se objetivamente, o próprio autor atrela-a à própria teleologia subjetiva de nosso nexo psíquico estrutural. De fato, para ele, a teleologia imanente do nexo estrutural de nossos sentimentos encontra a sua perfeição na criação de formações objetivas. ${ }^{17}$

Ao que tudo indica, é em meio a essa atmosfera, comungada por todos os indivíduos que a compõem, que pensamos, sentimos, queremos, decidimos e agimos em nossa singularidade, mas o que lutamos por conseguir, o conteúdo de nossas vivências, que formam o nosso nexo

15 Gesammelte Schriften, VII, pp. $146-147$

16 Gesammelte Schriften, VI, p. 137.

17 Cf. "Studien zur Grundlegung der Geisteswissenschaften", Gesammelte Schriften, VII, p. 57. 
psíquico adquirido em sua função reguladora de nosso agir, é um assunto provido pelo co-vivenciar das coisas comuns, isto é, extra-individualmente. Ora, é nessa atmosfera que buscamos o nosso aperfeiçoamento e desenvolvimento porque ela constitui o nosso verdadeiro hábitat, o único capaz de responder às necessidades de nossa estrutura psíquica teleologicamente organizada.

Assim alicerçados, torna-se mais fácil compreender a "relação especial" atribuída por Dilthey entre expressão, vida e compreensão: "Inteiramente diferente a expressão da vivência! Existe uma relação especial entre ela, a vida de onde ela provém e a compreensão que ela obtém. A saber, a expressão pode conter mais do nexo psíquico do que cada introspecção pode descobrir". ${ }^{18}$ De que "relação especial" então se trata?

Trata-se de uma relação apoiada na força catalisadora do pano de fundo constitutivo da vivência que, ao atuar como um fator extra-individual, garante objetividade a suas expressões, oferecendo-nos, por acréscimo, a possibilidade de compreendê-las. Isto porque o significado que os objetos e as pessoas adquirem para nós, em meio a essa esfera das coisas concebidas, apreciadas e valorizadas em comum, parece ser o único apoio sólido capaz de sustentar as raízes da objetividade das formas de expressão da vivência, responsável direta pela construção do mundo histórico, e conseqüentemente de sua compreensão como tarefa basilar das "ciências do espírito".

Vivência parece ser o verdadeiro ponto médio entre o geral e o individual, o universal e o singular, o ideal e o real, uma vez que, por constituição, carrega em si uma consciência eficaz e por isso consoladora e protetora de sua origem extra-individual, isto é, na "esfera das coisas comuns" a que pertence e que em certo sentido também lhe pertence. Se esse fundo comum também lhe pertence é porque os indivíduos, na singularidade de suas vivências, co-experimentam valores, objetivos, expressões, significados, crenças e, assim atuando, como que co-participam da criação ou construção desse todo a que pertencem e que lhes pertence também.

Já vimos, em seu Plano de Desenvolvimento para a Construção do Mundo Histórico nas Ciências do Espírito, que o nexo da vivência, em sua realidade concreta, repousa na categoria do significado, e que o sig-

18 Gesammelte Schriften, VII, p. 206. Cf. também Manfred Sommer, "Leben aus Erlebnissen, Dilthey und Mach", in: E. W. Orth (editor). Dilthey und der Wandel des Philosophiebegriffs seit dem 19. Jahrshundert, Alber, Freiburg München, 1984, p. 61. 
nificado não repousa em nenhum ponto fora da vivência, mas se encontra constitutivamente contido nela, ou melhor dizendo, em seu nexo. ${ }^{19}$

É o próprio Dilthey quem no referido plano nos garante que “... o significado exprime nada mais que integração num todo...". ${ }^{20}$ Então, dizer que o nexo da vivência repousa na categoria do significado é o mesmo que dizer que a relação parte-todo já está contida na vivência e a fundamenta, aliás, constitui o seu próprio nexo. E o autor acrescenta:

Toda vida tem seu próprio sentido. Ele se encontra em um nexo de significado, no qual todo presente passível de lembrança possui um valor próprio, portanto, possui, simultaneamente, no nexo da lembrança, uma relação com o significado do todo. Este sentido da existência individual é inteiramente singular, é irredutível ao conhecimento e representa seu modo, como uma mônada de Leibnitz, o universo histórico. ${ }^{21}$

De fato, o nexo da vivência parece traduzir-se completamente na relação parte-todo, relação esta que conta com o apoio do significado que a parte tem para o todo e vice-versa. Ora, isto significa dizer que esse universo se apóia inteiramente nas relações de significado entre o todo e as partes, entre o geral e o singular, entre o reino da uniformidade e o da individuação, relações estas que preparam o quadro fundamental do procedimento hermenêutico. Este, desenvolvido inicialmente em campos mais restritos como o da teologia, jurisprudência e filologia, passou a ser - graças ao esforço de Dilthey, no sentido de fundamentar as "ciências do espírito" com total independência em relação às ciências da natureza - aplicado ao campo mais amplo da vida em sua totalidade.

A publicação em 1960 da obra de Hans Georg Gadamer Verdade e Método, Fundamento de uma Hermenêutica Filosófica (1960) despertou grande interesse em todo mundo pelos problemas da hermenêutica, tornando-a um conceito de moda, fato este que teve suas repercussões sobre o recente voltar das atenções para a filosofia de Dilthey. E isto acontece como resultado de um reconhecimento sempre crescente dos filósofos da atualidade no sentido de fazer justiça àquele que foi, em seu tempo, um dos fundadores da hermenêutica.

19 Gesammelte Schriften, VII, p. 237

20 Idem, p. 230. Cf. também Gunter Scholtz, Zwischen Wissenschaftsanspruch und Orientierungsbedürfnis, Suhrkamp Taschenbuch Verlag, Frankfurt am Main, 1991, p. 266.

21 Idem, p. 199. Cf. também Frithjof Rodi, "Der Rhythmus des Lohens selbst, Hegel und Hölderling in der Sicht des Späten Dilthey", in: Reports on Philosophy, Jagiellonian University, Warsaw Cracow, 1987, pp. $107-120$. 
Otto Friedrich Bollnow pôde comprovar esse reconhecimento geral. Afirma ele, no primeiro volume de seus "Estudos sobre Hermenêutica", de 1982:

Hoje o conceito de hermenêutica, desenvolvido como procedimento das ciências histórico-filológicas, e já de longa data esquecido, voltou a ser usado. Por causa disso, pode-se compreender a filosofia de vida de Dilthey também como o esforço de fundamentação de uma "filosofia hermenêutica" ou uma "hermenêutica filosófica. ${ }^{22}$

A seu ver a posição histórico-filosófica de Dilthey pode ser melhor caracterizada como a de fundador da "hermenêutica filosófica". ${ }^{23}$

Dilthey aponta com clareza o processo de dissolução das bases teóricas das crenças práticas: as ciências positivas desfizeram as pressuposições que sustentavam a crença religiosa e as convicções filosóficas dos séculos anteriores. A realidade, dada com suas qualidades sensíveis, mostra-se como fenômeno do desconhecido. O maior trabalho da filosofia do século passado, a análise da consciência e do conhecimento, contribuiu de forma mais efetiva nesse trabalho de destruição. Espaço, tempo, causalidade, a própria realidade de um mundo exterior foram submetidos à dúvida. A consciência histórica dá provas cada vez mais claras da relatividade de toda doutrina metafísica ou religiosa, enfim, de toda convicção histórica. ${ }^{24}$

\section{Auto reflexão e a necessidade primordial de segurança prática}

A velha filosofia prática está morta, e aos olhos de Dilthey cumpre recriá-la, pois uma filosofia que não forneça regras para a ação prática, uma especulação sobre o mundo que não inclua uma visão de nossa vi-

22 Otto Friedrich Bollnow, Studien zur Hermeneutik, vol. I (Zur Philosophie der Geisteswissenschften), p. 195. Cf. também ders: Dilthey eine Einjührung in seine Philosophie, Novalis Verlag AG, Schaffausen, 1980, pp. 212 - 213.

23 Cf. Idem, cf. também Gunter Scholtz, "Was ist und seit wam gibt es 'hermeneutische Philosophie'?", in: F. Rodi (Hrsg.): Dilthey - Jahrbuch für Philosophie und Geschichte der Geisteswissenschaften, vol. 8 / 1993, Vandenhoeck \& Ruprecht in Göttingen, p. 103.

24 Cf. Idem, p. 194. Cf. também Gunter Scholtz (para quem Dilthey, tido como primeiro clássico da filosofia hermenêutica, teria descoberto essa crise), Philosophie VII (Hermeneutische Philosophie), in: Historiches Wörterbuch der Philosophie. 
da, nem mesmo um comando para sua conduta, é inteiramente insatisfatória. Só a filosofia prática, cheia de vida, é verdadeiramente ampla. Toda ciência teórica contém os pressupostos ou princípios necessários à colimação de determinados fins, reputados como valiosos. A determinação daquilo que, na vida, possui significado e valor constitui a tarefa da filosofia prática. O objeto desta consiste, pois, nos mais elevados princípios, por meio dos quais se fixam os caminhos e se estabelecem os fins da ação prática. ${ }^{25} \mathrm{O}$ balanço parte-todo, equilibrado hermeneuticamente pela categoria do significado, aponta insistentemente para o cumprimento daquela exigência fundamental da natureza humana, a saber, a de encontrar segurança e orientação práticas para a ação.

A filosofia, erigida à categoria de filosofia prática, deve necessariamente permitir extrair de seus conhecimentos teóricos princípios práticos reguladores não só da vida de seres singulares, assim como da sociedade como um todo. Cumpre-lhe, portanto, resgatar a soberania do espírito totalmente, aviltada pela autoridade onipotente do pensamento científico, em sua ânsia incontrolável de conhecer e dominar o mundo. Então, se cabe à filosofia oferecer fundamentação, esta não é apenas do conhecimento teórico, mas da ação humana prática. Ainda melhor, muito pelo contrário, o referido fundamento teórico para ser válido deve estar inteiramente subordinado aos interesses do agir humano em sua sede original de segurança prática. Só uma fundamentação com tais requisitos básicos poderia ousar alterar a composição da atmosfera caótica da cultura da época, tão penosamente viciada naquela separação entre o pensar e o agir, entre teoria e prática, entre conhecimento e ação, entre crenças teóricas e práticas, entre soberania do conhecimento e do espírito, entre ciências particulares e filosofia, natureza e histórica, vivência e compreensão..., separações estas fatalmente nefastas aos propósitos de uma vida humana saudável, pelo menos dentro dos limites do cenário da "filosofia da vida".

A essa fundamentação aparentemente mágica do pensar e do agir da teoria e da prática... Dilthey atribui o nome de "auto-reflexão". Tomemos suas próprias palavras em seu ensaio "Vista Geral de Meu Sistema" (1911):

A fundamentação da filosofia não é apenas a do conhecimento teórico: em filosofia trata-se, pois, de uma elevação do espírito a sua autonomia: esta con-

25 Cf. Gesammelte Schriften, X, pp. $13-14$ 
suma-se não só por meio de conhecimento válido universalmente como por meio da determinação universal de valores e regras do agir teleológico. Uma fundamentação que abrange esses diferentes campos, como teoria do conhecimento, lógica e teoria do método da compreensão do real, assim como essência das próprias teorias sobre determinação de valores e atos de acordo com fins, pode ser designada como auto-reflexão. ${ }^{26}$

Essa afirmação, tomada em primeiro plano, nos dá a impressão de que a fundamentação oferecida pela filosofia é dupla, isto é, deve incluir um apoio universal não só para o conhecimento como para a determinação de valores e estabelecimento de fins para a ação. De um lado, então, um fundamento teórico, e de outro, um fundamento prático. Todavia, se ultrapassarmos os limites de um plano em direção ao outro podemos perceber que o que parecia ser duplo encontra-se originalmente apoiado em uma unidade.

Em A Construção do Mundo Histórico nas Ciências do Espírito, Dilthey afirma com clareza: "A célula original do mundo histórico é a vivência, na qual o sujeito se encontra em interação recíproca de vida com seu meio. Este meio atua sobre o sujeito e recebe efeitos dele". ${ }^{27}$ Ora, essa interação recíproca do sujeito com o meio parece ser o fato primeiro, a categoria fundamental da realidade humana histórico-social. O conhecimento está, ao que tudo indica, relegado a uma posição derivada, secundária por origem, pois prende-se ao processo em virtude do qual se mantém e se desenvolve a própria vida. Uma conhecida frase do Tratado da Realidade (1890) não nos permite, como já vimos, ter qualquer dúvida a esse respeito: "Os pressupostos fundamentais do conhecimento estão dados na vida e o pensamento não pode conceber por trás deles". ${ }^{28}$

Com esse princípio metodológico fundamental, isto é, de que "o pensamento não pode ir além da própria vida", Dilthey está pretendendo alcançar um alvo mais distante, isto é, a crítica à metafísica com sua vã pretensão de encontrar um apoio transcendentalmente seguro e sólido para o conhecimento. Para isso faz residir na vida, por meio de sua expressão microscópica, a vivência, todas as categorias da realidade

26 Gesammelte Schriften, VIII, p. 179. Cf. também Manfred Riedel, "Hermeneutik und Erkeuntnis zum Verhältnis von theoretischem Wissen und praktischer Lebensgewissheit bei Wilhelm Dilthey, in: F. Rodi und H. U. Lessing (Hrsg.), Materialien Zur Philosophie W. Dilthey, Suhrkamp Frankfurt am Main, 1984., p. 381.

27 Gesammelte Schriften, VII, p. 161

28 Gesammelte Schriften, V, p. 136 
objetiva. E, assim, a vivência pode ser a sua própria prova, pois ela traz em si o seu próprio critério de verdade. É o que podemos apreender da seguinte afirmação do autor, incluída em seu "Esboço de Berlim" (1893):

Como a origem do juízo e do conhecimento está na vida, assim também o seu fim está nela mesma. A vida é, de acordo com sua própria estrutura, através do aumento da consciência por sobre os objetos exteriores, de acordo com a sua natureza, com o seu modo de operar os meios, de provocá-los ou afastá-los, teleologicamente condicionada. Ela é, por outro lado, condicionada pelo aumento de reflexão sobre valores e os fins que surgem na percepção interna. ${ }^{29}$

Não estamos mais diante daquele clima da catástrofe iminente, descrito por Dilthey como próprio da cultura de sua época.

A tarefa de fundamentar a filosofia contemporânea por meio da auto-reflexão do homem e da reflexão da sociedade sobre si mesma tarefa esta que se efetiva na transposição dos dualismos tão nefastos à compreensão da vida em seu nexo estrutural ou em sua unidade fundamental - tem necessariamente como ponto de partida a consciência da própria vida. Poderíamos perguntar, todavia, de onde essa "atitude consciente diante da vida" extrai a sua força fundamental de unidade com capacidade para nos oferecer orientação consciente ante as diversidades, oposições e contradições que povoam a vida humana histórica em sua profundidade enigmática? Ou, de que modo uma atitude consciente perante a vida pode ultrapassar todos os problemas particulares, além dos meios e fins do conhecimento particular? Ou ainda, como a consciência da própria vida pode nos conduzir ao reino do universal? A solução desta questão parece ligar-se a uma resposta de Dilthey a uma pergunta formulada por ele próprio. O autor, referindo-se àquela ameaça de catástrofe iminente dentro da cultura de sua época, propõe:

"A questão é, pois, principalmente, quais as forças que podem ser mobilizadas para dominar essa influência. Pois bem, meu livro Introdução às Ciências do Espírito resultou da convicção de que a autonomia das "ciências do espírito" e do conhecimento da realidade histórica, contido nelas, poderia contribuir para isto. Expresso de outro modo: o mundo histórico conduz, por meio da autoreflexão, a uma vitalidade de vitoriosa espontaneidade, a um nexo não passível de formulação pelo pensamento, mas analiticamente apresentável na vida individual e na interação; finalmente, leva a um nexo mais elevado, de tipo especial que transcende os recursos científico-naturais; este nexo precisa ser salientado

29 Gesammelte Schriften, XIX, p. 320. 
e proclamado com vigor se é que nos interessa o reavivar de sua importância superior, consciente do próprio valor. ${ }^{30}$

O exercício da "auto-reflexão" permite-nos, então, intuir nossa comunhão com a fonte de toda vitalidade humana, isto é, estimula e alimenta a volta da consciência sobre si mesma e com isto reforça, fortalecendo o nexo entre a vida histórica individual e a energia vital de extraordinária espontaneidade. As qualidades características dessa vitalidade ou desse nexo: não é apreensível pelo pensamento, mas pode ser intuído na vida singular, na interação entre os indivíduos e, finalmente, uma vez depurado de seus contornos históricos, o referido nexo revela seu tipo especial não acessível aos recursos científicos naturais. Estes, embora muito precisos e rigorosos, mostram-se inteiramente insensíveis e impotentes para captar uma vitalidade tão extraordinariamente espontânea ou um nexo tão especial na sua composição. Se não nos cabe pensar nele ou provar a sua existência com o apoio de recursos científico-naturais, cumpre-nos, sim, proclamá-lo vigorosamente, reavivá-lo em nossa fé em sua importância superior. Como estamos percebendo, a "auto-reflexão" nos convida a reforçar nossa comunhão com a fonte original de energia vital. Essa fonte, ao alimentar os nexos vitais singulares, parece elevá-los à categoria de nexos especiais inteiramente indiferentes à apreensão limitada dos recursos meramente naturais. A especialidade desses nexos parece dever-se ao fato de eles expressarem continuamente a religação parte-todo.

Nossa vida psíquica, em sua totalidade de funções, estará instrumentalmente sempre voltada para exteriorizar a ligação das partes que cada um de nós representa - com o todo que nos envolve e nos alimenta com sua energia infinita, ligação esta que simboliza o estado mais profundo da consciência de nossa própria vida e, neste sentido, a condição mais primitiva de possibilidade da compreensão humana. Assim, já em sua origem tão fundamentalmente apoiada, pode a atitude humana diante da vida tornar a "auto-reflexão do homem" e a "reflexão da sociedade sobre si mesma" de fato efetivas, cumprindo à risca a tarefa basilar de filosofia contemporânea. "Auto-reflexão" parece ser, então, a denominação escolhida por Dilthey como símbolo desse retroceder consciente à fonte original de energia vital do mundo humano histórico-social.

30 Briefwechsel Dilthey - Yorck, pp. 156 - 157. Grifo do autor. 


\section{A auto-reflexão e a tarefa de filosofia contemporânea}

Dilthey, ao seguir o caminho de uma "crítica da razão histórica" ou da "descrição da vida", tem como objetivo fundamentar teoricamente o conhecimento da realidade histórico-social, erigindo-o assim à categoria de objeto de estudo autônomo das "ciências do espírito". Chegou mesmo a atribuir o nome de "auto-reflexão epistemológica" a essa tentativa de analisar criticamente as condições "teóricas" do conhecimento histórico. Suas palavras na Introdução às Ciências do Espírito (1883) parecem não nos permitir qualquer equívoco a esse respeito:

O conhecimento do todo da realidade histórico-social ao encontro do qual nós nos sentimos empurrados, por ser o problema mais geral e último das ciências do espírito, realiza-se sucessivamente em um nexo de verdades que se apóiam na auto-reflexão epistemológica, nexo no qual as teorias particulares da realidade social se erguem sobre a teoria do homem. Estas, todavia, serão empregadas em uma verdadeira ciência histórica progressiva, para esclarecer sempre mais a realidade histórica ligada à ação recíproca dos indivíduos. Nesse nexo de verdades reconhecer-se-á a relação entre fato, lei e regra por meio da auto-reflexão. Dele resulta também quão longe nós ainda estamos de uma possibilidade previsível de uma teoria geral da evolução histórica, se é que podemos falar de uma tal teoria por mais modesto que seja o seu sentido. História universal, na medida em que não fosse algo sobre-humano, constituiria a conclusão desse todo das ciências do espírito. ${ }^{31}$

Cabe-nos inicialmente perguntar que "nexo de verdades" é este que oferece apoio ao conhecimento sucessivo do todo da realidade histórico-social e que encontra seu próprio apoio na "auto-reflexão epistemológica"? Ora, se o conhecimento da realidade histórico-social apóiase em um "nexo de verdades" que, por sua vez, encontra sua fundamentação na "auto-reflexão epistemológica", então estamos diante de um conhecimento que se autofundamenta, isto é, ele se apóia no processo circular de consciência diante da própria vida, que por sua vez nos conduz à consciência da unidade original. Na verdade, ele já nasce válido e objetivo e por isto não precisa de qualquer fundamentação. Ele é a sua própria prova. Prová-lo é uma redundância, é uma volta sobre ele mesmo. Isto porque o ato de conhecer resume-se na exteriorização de algo desde sempre conhecido. E auto-reflexão epistemológica é apenas o re-

31 Gesammelte Schriften, I, p. 95. 
descobrir contínuo do "nexo de verdades" aí desde sempre implícito, ou o efetivar da religação viva das partes com o todo, ou o restabelecer, o reatar do vínculo entre energia original e vitalidade extraordinariamente espontânea das criações humanas históricas, ou melhor ainda, o reviver da experiência da unidade original do homem com o absoluto, da individualidade com a totalidade, da razão com a vida, da ciência com a intuição. Como sabemos, todos esses contrários encontram-se como que indissoluvelmente unidos na cédula original do mundo históricosocial, isto é, na vivência.

O lacre que garante a inviolabilidade desse entrelaçamento: energia original e "vitalidade extraordinariamente espontânea" é a "consciência da própria vida" ou "atitude consciente diante da vida". A autoconsciência confere veracidade e validade ao pensamento e às ações humanas resultantes do balanço equilibrado dos valores experimentados pelos sentimentos, e da determinação de fins, pela vontade. Se isto acontece é porque, como vimos, todo o pensar e o agir conscientes encontram-se como que teleologicamente voltados para restabelecer continuamente a ligação das partes com o todo e extraem daí, e somente daí, o seu significado de verdade, o seu valor. Afinal, como vimos, a categoria do significado como fundamental dentro do mundo histórico-social, caracteriza-se por ser nada além do que "... a integração num todo; neste todo porém o enigma da vida (...) é eliminado...", ${ }^{32}$ conforme o autor declara em seu Plano de Desenvolvimento para a Construção do Mundo Histórico nas Ciências do Espírito. A auto-reflexão progressiva dessa "realidade histórica", advinda das "ações recíprocas entre os indivíduos", proporcionar-nos-á lentamente o desvelar do caráter enigmático da vida humana por meio da apreensão gradativa do nexo de verdades. De fato, auto-reflexão significa propriamente a elevação do espírito à consciência de si mesmo, isto é, sobre as suas próprias criações históricas, procurando desvendar no interior de cada uma delas a força sempre presente de sua absoluta soberania condutora.

As palavras do autor em a "Vista Geral do Meu Sistema" (1911) parecem ser bastante claras a esse respeito: "O método dessa auto-reflexão é a análise que disseca todos os produtos e funções da Humanidade, desde as ciências até a vida política, para procurar na consciência as condições não mais redutíveis dela própria". ${ }^{33}$ Ora, as condições não

32 Gesammelte Schriften, VII, p. 230.

33 Gesammelte Schriften, VIII, p. 179. 
mais passíveis de redução, portanto, as absolutamente simples, primitivas, genuínas e legítimas da consciência, isto é, as verdadeiramente puras e autênticas, para além das quais não nos é possível regredir, só podem ser descobertas pelo curvar do espírito sobre si mesmo e suas criações, naquele seu esforço de auto-reflexão. Após "dissecar todos os produtos e funções da Humanidade" historicamente condicionados, esse procedimento auto-reflexivo do espírito contempla-nos com o vivenciar de momentos de profunda unidade entre consciência finita e soberania do espírito infinito. Só aqui parecem cravar-se as condições verdadeiramente puras e autênticas da consciência, já que são as mais simples e primitivas, por isso mesmo as absolutamente legítimas.

Fundamentar o conhecimento dessas ciências é a grande tarefa da "filosofia da vida". Trabalho nada contundente se levarmos em consideração que vida e espírito penetram as formas objetivas das vivências em seu trabalho de tecer a realidade histórico-social, transformando-a na "grande realidade exterior do espírito". Efetiva-se assim a síntese que o espírito representa: o exterior revela o interior, a natureza o espírito, o ato a potência, a ação a energia original, a subjetividade a objetividade, a vivência a vida universal... E o espírito garante sem sombra de dúvida a possibilidade de compreensão do mundo histórico-social, mundo este que ao ser tecido conjuntamente com essa energia infinita adquire foros de universalidade em sua própria origem. É como se manifestando o interior pelo exterior, fosse dado corpo ao espírito, e revestindo de realidade exterior aquilo que era apenas uma energia em potencial obtivéssemos a garantia de uma forma lógica de conhecê-lo, pensá-lo ou compreendê-lo.

É justamente neste ponto que se encaixa o trabalho efetivo das "ciências do espírito" em busca da sistematização do conhecimento da grande "realidade exterior do espírito". Caberá às "ciências do espírito" "... antes de mais nada e principalmente retraduzir a imensa e extensa exteriorização da realidade humana histórico-social na vitalidade espiritual de onde ela proveio". ${ }^{34}$ Ao que tudo indica, esse procedimento de retradução adquire sua validade por constituir apenas a outra face do agir espiritual. É justamente pelo fato de o próprio espírito exteriorizarse em obras ou criações que ele é capaz de retroceder ás origens, retraduzir, interiorizar sua criação, compreendê-la portanto. Interior e exterior, tradução e retradução, vivência e compreensão parecem apenas

34 Idem, pp. $119-120$. 
duas perspectivas, dois momentos da vida do espírito. Ter consciência viva dessa dupla face do espírito é o mesmo que reforçar o nosso nexo vital ou a nossa unidade com essa energia espiritual. Como sabemos, o nexo de nossa própria consciência é para o autor a condição mais geral de vida. E como tal, é condição fundamental da auto-reflexão erigida pelo autor em princípio basilar da "filosofia da vida".

Se a consciência tem condições de voltar-se sobre si mesma, de conhecer-se a si mesma, ao fazê-lo, ao voltar-se sobre si mesma, ela se conhece como consciência, o que significa dizer como nexo; como unidade entre espírito universal e história, vida e vivência... E Dilthey continua em sua obra A Construção do Mundo Histórico nas Ciências do Espírito (1910) expondo com clareza seu pensamento: "É a direção para a auto-reflexão, é o caminho da compreensão do exterior para o interior. Essa tendência utiliza cada exteriorização da vida para a compreensão do interior, de onde ela resultou". ${ }^{35}$ Ora, essa verdadeira síntese que constitui a essência do espírito e que nos permite captá-lo na história como potência e ato, energia e criação, interior e exterior, princípio e ação, parece aproximar-nos inevitavelmente do pensamento hegeliano em sua caracterização da história como aquele movimento em que o "espírito em si" se exterioriza em obras culturais, sendo por isso capaz de interiorizar a sua criação, isto é, voltá-la "para si", compreendê-la como realização sua.

Esse verdadeiro toque de afinidade com o conceito hegeliano de espírito parece encontrar respaldo em muitas passagens da obra diltheyana, em que o autor faz referências a Hegel quase como um ponto de partida necessário para justificar certos aspectos característicos de sua "filosofia da vida", entre eles especialmente o seu conceito de espírito objetivo. ${ }^{36}$

A título de ilustração poderíamos, ainda que de modo superficial, evocar o conceito de Hegel de história como o movimento pelo qual o espírito se exterioriza, se manifesta, produzindo as obras culturais, e reconhecendo-se como seu criador, interioriza-as, compreende-as. Nesta exata medida, história é reflexão e sua tarefa completar-se-á quando o espírito dobrar-se totalmente sobre si mesmo, interiorizando, compreen-

35 Idem, p. 82. Cf. também G. Pfafferott. "Die Bedeutung des Begriffs Selbstbesinnung bei Dilthey und Husserl", in: E. W. Orth (Hrsg.), Dilthey und die Philosophie der Gegenwart, Alber, München, Freiburg, 1985, pp. $351-380$.

36 A esse respeito cf. Amaral, M. Nazaré C. P.. Dilthey: Conceito de Vida e Pedagogia. São Paulo:Ed. Perspectiva, EDUSP, 1987 
dendo completamente a sua trajetória histórica para pairar absolutamente, agora já não mais dentro dos domínios da história, mas sim da filosofia. Com efeito, o caminho da objetivação da vida que torna possível o seu reverso, isto é, o da "auto-reflexão" e com ele o da "filosofia da filosofia", forma com eles o duplo movimento de ida e volta, isto é, da vivência e da compreensão que sustenta toda a construção diltheyana do mundo histórico, impondo condições à possibilidade de sua compreensão.

Nosso interior animado pela ligação original com a energia vital oferece-nos o único ponto de partida para compreendermos a história e o poder que o conceito de progresso tem para o homem. Na verdade, progresso é sinônimo da manifestação, do desvelar lento de um trabalho humano de vida feliz, na consciência da unidade com a energia original. Não se trata, é bem verdade, de um objetivo, mas de um caminhar eterno da humanidade. Por isso não é uma tarefa do homem particular e sim do homem histórico. Este, ao agir, deve manifestar a sua religação com o todo, com a unidade original. Só assim cada um estará participando ativamente daquele trabalho de vida histórico da Humanidade e, só assim a vida adquirirá significado.

Também o "princípio da fenomenalidade", conhecido como ponto de partida da "filosofia da vida", "da realidade" ou "da experiência", ou ainda empiria, em oposição a empirismo, parece extrair toda a sua força "empírica" dessa experiência humana da unidade original. Para tanto, cumpre-nos relembrar o que ele nos prescreve em seu ensaio "Filosofia da Experiência Empiria, não Empirismo" (anterior a 1880):

O real, que como coisa ou objeto se distingue de mim mesmo, me é dado somente na minha consciência, naquela do meu eu. O real é aquilo que atua em minha totalidade psíquica. Todos os fatos e todas as verdades são dados para mim em mim mesmo. A minha consciência é o único lugar de sua existência, atos psíquicos constituem o único elemento do qual eles são tecidos. Eles não são nada além do que algo espiritual. Todavia, esse princípio precisa ser compreendido nos seus verdadeiros limites. ${ }^{37}$

Sabemos que para compreender esse princípio dentro de seus verdadeiros limites a condição fundamental nos é dada, conforme já vimos, pelo sinal vermelho aceso ao fenomenalismo, segundo Dilthey, estilizado na conhecida frase de Schopenhauer: "O real é minha repre-

37 Gesammelte Schriften, IX, p. 17Cf. também José Ortega y Gasset, Obras Completas, Revista de Occidente, Tomo VI, Madrid, pp. 192 - 193. 
sentação". Sabemos que as vivências constituem o critério responsável pela triagem dos fatos da consciência, e conseqüentemente daquele material responsável pela caracterização do real. Vivência é aquela experiência viva mais distintivamente humana, pois o seu conteúdo é formado pela atuação da totalidade de nossas forças psíquicas. Estas são como que acionadas pela resistência exercida por um mundo exterior sobre os movimentos de nosso corpo, sobre o impulso de minha vontade, respondendo assim pelo surgimento dos fatos da consciência. Estes, por sua vez, encontram-se totalmente submetidos às condições "reais" ou verdadeiras ou "vivas" da consciência, isto é, às condições "históricas".

Não podemos nos esquecer que é papel da auto-reflexão desenvolver a análise de modo tão radical a ponto de dissecar todos os produtos e funções da Humanidade desde as ciências até a vida política, tendo em vista captar na consciência "as condições não mais redutíveis da consciência". 38 Trata-se, na verdade, de buscar as condições "históricas" do desenvolvimento de uma consciência que evolui de fato historicamente, mas a partir da sucessão de momentos sintáticos entre vida e história, todo e partes. Aqui parecem enraizar-se as condições "reais" ou "vivas" da consciência histórica. É justamente nesse nexo, nessa unidade, nessa identidade entre energia espiritual e suas expressões objetivas que podemos captar essas "condições" ou "pressuposições" da consciência que não são mais redutíveis. Referimo-nos à consciência da unidade original, a única capaz de garantir para todo o sempre as condições verdadeiramente "históricas" da consciência... tornandoa capaz de compreender o desvelar lento e progressivo da energia infinita do espírito... E aqui parece alicerçar-se também mais fundamentalmente o conhecido "princípio da fenomenalidade", como o mais sólido ponto de partida da "filosofia da experiência" ou "empiria em oposição ao empirismo".

De fato, o real não é produto de minha representação, mas da vivência que configura a manifestação histórica dessa comunhão humana com a fonte da energia espiritual, ou com a vida, o que faz com que o autor, uma vez tão bem alicerçado, passe daí para a frente a sustentar a força exclusivamente empírica da identificação entre realidade e experiência, expressa na denominação atribuída à sua própria filosofia, isto é, "filosofia da realidade ou da experiência". Da mesma forma justificase a mais harmoniosa identificação entre o sujeito e o objeto. E essa har-

38 Cf. "Übersicht meines Systems", Gesammelte Schriften, VIII, p. 179. 
monia tem a sua razão de ser porque, ao que tudo indica, não há o perigo da prática do reducionismo, nem para o lado do sujeito nem para o do objeto. Isto porque sujeito e objeto estão amalgamados pelos poderes absolutos da verdade do espírito, que penetra a ambos indistintamente.

Parece consolidar-se a tarefa de filosofia contemporânea, qual seja: "auto-reflexão do homem e reflexão da sociedade sobre si mesma" ${ }^{39} \mathrm{~A}$ referida tarefa encontra-se atrelada a um procedimento verdadeiramente hermenêutico que conta, por sua vez, com a força da lógica interior à própria vida, lógica esta que se expressa dialeticamente na fórmula hermenêutica: Vida = todo + vida = parte. De fato, Dilthey aponta em seu Plano de Desenvolvimento para a Construção do Mundo Histórico nas Ciências do Espírito, entre os predicados da vida, a "lógica interna" e a "dialética interna". ${ }^{40} \mathrm{E}$ é justamente no balanço dialético dessa lógica interna que a categoria significado se alicerça. E, como sabemos, “... significado nada mais exprime do que a integração num todo; neste todo, porém, o enigma da vida (...) é eliminado...". ${ }^{41} \mathrm{Sim}$, a categoria do significado aponta a necessidade da religação da parte ao todo e assim restabelecer a unidade ou compreender a vida. Poderíamos dizer que "vida = todo" é a direção eterna da "vida = parte".

Finalmente, acreditamos que, ao salientar a importância da sentença hermenêutica para compreensão da "filosofia da vida" buscamos, de algum modo, apreender as raízes da própria hermenêutica diltheyana. Baseados nesse procedimento julgamos ser possível esclarecer o que Jürgen Habermas chama de inconseqüência do pensamento diltheyano. Esta prender-se-ia ao fato de Dilthey buscar uma elucidação hermenêutica do mundo histórico e ao mesmo tempo querer apreendê-lo positivamente de acordo com o modelo do ideal de objetividade científiconatural. ${ }^{42}$ Nós seríamos ainda mais radicais do que Habermas em seu julgamento, pois poderíamos detectar nessa submissão diltheyana ao ideal de objetividade das ciências naturais uma monstruosa contradição com o sentido fundamental de sua peregrinação filosófica como um todo. Se ele empenhou todo o seu esforço, se ele dedicou toda a sua vida, como confessa com freqüência, tendo em vista fundamentar as "ciências do espírito" independentemente dos métodos e princípios

\footnotetext{
39 Cf. "Berliner Entwurt", Gesammelte Schriften, XIX, p. 304.

40 Gesammelte Schriften, VII, p. 238

41 Idem, p. 230.

42 Cf. Jürgen Habermas, Erkenntnis und Interesse, Frankfurt/ M. 1968, pp. 229 ss.
} 
das ciências naturais, como poderia deixar transparecer tamanha inconsistência de pensamento?

Esse verdadeiro "impasse" ou "inconseqüência", para usar as palavras de Habermas, parece encontrar a nosso ver uma solução bastante plausível, à medida que nos permitimos entrever que a força que sustenta o arcabouço teórico do pensamento de Dilthey provém das raízes mais subterrâneas da intuição, da crença do autor na unidade original entre parte-todo, humanidade-divindade, história-vida, singular-universal, consciência histórica e espírito soberano. Aí sim parece localizar-se toda a energia de sua hermenêutica filosófica, e conseqüentemente da possibilidade de compreensão da realidade humana histórico-social.

Se o autor pode "descrever a vida" em plena "objetividade" de pensamento é porque a referida objetividade está garantida pela universalidade de uma compreensão anterior da vida, compreensão esta fundada na fé. Ao que tudo indica, o esclarecimento hermenêutico do mundo histórico pode ser plenamente consoante com a exigência de objetividade do pensamento diltheyano, desde que a referida objetividade floresça não do modelo científico natural, mas da universalidade da fé inerente à experiência humana da unidade original.

É preciso perguntar, contudo, se - a partir de tão grande confiança depositada no papel das ciências do espírito - semelhante tarefa não estaria situada em nível muito elevado, sem preocupação maior com os limites da compreensão. O próprio Dilthey chamou a atenção, em diferentes pontos de sua obra, para tais limites. De modo drástico, fala ele em sua última aula a respeito das dificuldades de compreensão dentro dos contornos da vida cotidiana: entre os sexos, em relação com as crianças, mas também em relação às convenções, fingimento e mentira, além de diferentes reações emocionais que influenciam nossas relações com outros seres humanos. ${ }^{43}$

Exatamente esse último ponto é também importante na análise diltheyana das "relações vitais" que se estabelecem entre o indivíduo e seu meio:

não há nenhum ser humano ou qualquer coisa que fossem para mim, apenas objeto e não pressão ou estímulo, objetivo a ser alcançado ou compromisso da vontade e que não representassem importância ou exigência de respeito e atração interior ou obstáculo, distância e estranhamento. ${ }^{44}$

43 Cf. System der Philosophie in Grundzügen, Gesammelte Schriften, XX, p. 100.

44 Gesammelte Schriften, VII, p. 131. 
Dilthey não estaria mencionando aqui aspectos metodológicos, mas antes, fenomenológicos das estruturas vitais cotidianas. Além dessas, encontramos reflexões no campo das questões psicológicas da compreensão do outro. A interpretação de expressões que nos causam estranhamento pode ser bastante diferenciada, dependendo do conhecimento do contexto ao qual uma tal expressão pertença, ou de acordo com o tipo de vida mental que sem qualquer reflexão as apóiam na maioria dos casos.

E os limites da nossa compreensão residem sempre ali onde não podemos mais compreender para além do contexto. ${ }^{45}$ Com isso evidenciase o fenômeno do estranhamento como o verdadeiro limite da compreensão. Para Dilthey,

a tarefa de compreender seria impossível se as manifestações vitais nos fossem inteiramente estranhas e seria desnecessária se não existisse nas manifestações vitais algo estranho. O sentido da compreensão repousa entre esses dois pólos opostos. Ela é requerida onde existe algo estranho que a arte de compreensão deve apropriar-se. ${ }^{46}$

Um outro aspecto de limitação de nossa compreensão repousa na facticidade das estruturas vitais elementares, inteiramente impermeável à compreensão:

O ponto central de toda incompreensão são fertilização, nascimento, desenvolvimento e morte. O ser vivo sabe da morte e apesar disso não a pode compreender. A nós, que estamos vivos, nos é incompreensível a morte no primeiro momento em que a presenciamos, e aqui repousa acima de tudo nossa atitude em relação ao mundo como o outro, o estranho, o terrível. ${ }^{47}$

Em relação a todas essas indicações sobre os limites de nossa compreensão, Dilthey mantém-se firme na tarefa de alargá-los o máximo possível por meio da auto-reflexão. Assim, destaca os limites da compreensão para o trabalho de interpretação nas ciências do espírito, e salienta a tarefa de compreender como "processo intelectual de elevado esforço e enquanto tal uma atividade infinita". ${ }^{8}$ Mas ele assegura,

45 Cf. Gesammelte Schriften, V, p. 277.

46 Gesammelte Schriften, VII, p. 225.

47 Gesammelte Schriften, VII, p. 80 sS; cf. também VIII, 143

48 Gesammelte Schriften, VII, p. 277. 
como Schleiermacher, que a verdadeira vida das ciências do espírito, e com isso da própria auto-reflexão da sociedade, reside exatamente na tarefa infindável da compreensão.

AMARAL, M. N. C. P. de. Dilthey - Concept of experience and the limits of the understanding in the sciences of the spirit. Trans/Form/Ação, (São Paulo), v.27 (2), p.51-73, 2004.

- ABSTRACT: Dilthey's overall goal of a Critic of Historical Reason Will require a progression from an immediate kind of knowledge of life to the conceptual cognition of the human sciences, to a reflective knowledge that constitutes mature understanding. This paper intends to show, which are the difficulties and the limits of Dilthey's theoretical enterprise.

- KEYWORDS: experience; expression; understanding; self-reflection; objective spirit 